\title{
BMJ Open Dynamic balance and ankle injury odds: a prospective study in 196 Dutch physical education teacher education students
}

\author{
Sander Bliekendaal (1D , ${ }^{1}$ Janine Stubbe, ${ }^{2,3,4,5}$ Evert Verhagen ${ }^{6,7,8}$
}

To cite: Bliekendaal S,

Stubbe J, Verhagen E. Dynamic balance and ankle injury odds: a prospective study in 196 Dutch physical education teacher education students. BMJ Open 2019;9:e032155. doi:10.1136/ bmjopen-2019-032155

- Prepublication history for this paper is available online. To view these files, please visit the journal online (http://dx.doi. org/10.1136/bmjopen-2019032155).

Received 05 June 2019 Revised 29 November 2019 Accepted 04 December 2019

Check for updates

(C) Author(s) (or their employer(s)) 2019. Re-use permitted under CC BY-NC. No commercial re-use. See rights and permissions. Published by BMJ.

For numbered affiliations see end of article.

Correspondence to Sander Bliekendaal; s.bliekendaal@hva.nl

\section{ABSTRACT}

Objective The aim of this study was to investigate whether dynamic balance, measured with the anterior component of the Star Excursion Balance Test (SEBT-ANT), is a risk factor for ankle injuries in physical education teacher education (PETE) students.

Design and setting A prospective monocentre study in first-year PETE students.

Participants A total of 196 subjects, of which 137 men $(70 \%)$ and 59 women $(30 \%)$.

Outcome measures This study consisted of measures of the SEBT-ANT at baseline (September 2015) and an injury registration procedure during a follow-up period (September 2015-June 2016). The association between the SEBT-ANT score and subsequent ankle injury was analysed with generalised estimating equations analysis at the leg level.

Results Men and women had an average SEBT-ANT score of, respectively, $65.1 \%$ and $67.7 \%$ of leg length. In $20(15 \%)$ subjects, the first injured body site involved the ankle. Across all participants, a below average SEBT-ANT score was not associated with increased ankle injury odds ( $\mathrm{OR} \mathrm{OR}=2.43,95 \% \mathrm{Cl}: 0.94$ to $6.29, \mathrm{p}=0.07$ ). In men, a below average SEBT-ANT score indicated sevenfold increased odds for ankle injury (OR=7.06, $95 \% \mathrm{Cl}: 1.43$ to $34.92, p=0.02)$. In women, this relationship was not significant $(\mathrm{OR}=0.72,95 \% \mathrm{Cl}$ : 0.19 to $2.71, \mathrm{p}=0.62)$.

Conclusions Below average normalised SEBT-ANT scores were associated with sevenfold likelihood for ankle injuries in men. In contrast, no relationship was found for the SEBT-ANT score and ankle injuries in woman. These results may provide directions for the implementation of screening tools, as part of an injury prevention programme, to identify male PETE students with an increased likelihood for ankle injuries.

\section{INTRODUCTION}

Physical activity and sport participation are essential for maintaining and improving health. ${ }^{12}$ The downside of physical activity and sport participation is, however, the risk for sustaining an injury. ${ }^{3}$ physical education teacher education (PETE) students participate, as part of the PETE curriculum, in a wide range of physical activities, which puts them at risk for sustaining an injury. ${ }^{4}$ Injured
Strengths and limitations of this study

To the best of our knowledge, this was the first study on dynamic balance as a risk factor for ankle injuries in physical education teacher educations (PETE) students.

- In addition, strengths of this study are the prospective study design, the relatively long follow-up period ( 10 months) and the relatively high response rate (81\%).

- Furthermore, our study used generalised estimating equation analysis at the leg level and controlled the model by person and previous ankle injury.

- The self-evaluated injury registration and the low number of ankle injuries limits the strength of this study.

- The results of this study have limited clinical relevance as they are based on a single sample of PETE students.

students are limited to participate in the educational programme, which can cause a suboptimal professional development, higher study costs and, in extreme cases, exclusion from the PETE programme. Therefore, prevention of injuries in this population is needed.

According to the 'sequence of prevention' model by van Mechelen et $a l^{5}$ knowledge about the injury problem and associated risk factors are needed before preventive measures can be developed. Several studies have described the injury problem in PETE students and indicate that the ankle is in the top three of injury localisations in this population. ${ }^{4-9}$ In the literature, one of the most significant risk factors for ankle injuries is dynamic balance of the ankle. ${ }^{10-12}$ A common and practical method to assess dynamic balance of the ankle is the Star Excursion Balance Test (SEBT). ${ }^{13-20}$ The literature shows that, in athletic populations, low scores on the anterior component of the SEBT (SEBT-ANT) are associated with an increased 
risk for lower extremity injuries in general ${ }^{131718}$ and ankle injuries in particular. ${ }^{16} 20$

However, no studies are found in the literature regarding dynamic balance as a risk factor for ankle injuries in PETE students. In addition, because of differences in characteristics between the PETE and sport-specific population, the existing literature on this topic has limited transferability to the PETE population. Therefore, the aim of this study was to investigate whether dynamic balance, measured with the SEBT-ANT, is a risk factor for ankle injuries in PETE students. Based on the literature, it was hypothesised that dynamic balance would be a risk factor for ankle injury. Identifying significant risk factors for ankle injuries can be of importance in the development of an injury prevention programme in the PETE population.

\section{METHODS}

\section{Subjects}

The study population consisted of first-year PETE students of the Amsterdam University of Applied Sciences. The first-year PETE curriculum consisted of, apart from theoretical courses, an average weekly sport exposition of approximately 10.5 hours in six different sports (athletics, dance, field sports, gymnastics, martial arts and swimming). In total, 229 students enrolled the academic year 2015-2016. Exclusion criteria for subjects were: (1) no participation in the physical test/inability to perform the physical test and (2) no response in injury surveillance.

\section{Study procedure}

A prospective study design was used. At the start of the academic year all subjects were informed about the study design and procedures during a plenary presentation and were asked to complete an informed consent. A baseline questionnaire, which was completed by the subjects after the plenary presentation, was used to obtain data regarding sport participation, gender, age and ankle injury history in the past 12 months (yes/no). During the first week of the study subjects underwent a preparticipation examination by a sport physician, including measures of length and body weight, and a physical screening including the SEBT-ANT as a measure for dynamic balance of the ankle (ANT relative to leg length). An injury surveillance procedure was conducted during the following academic year to obtain data regarding sport participation (average hours/week) and subsequent injuries.

\section{Star Excursion Balance Test}

The SEBT was used as a measure for dynamic balance of the ankle. ${ }^{17}$ Different applications of this protocol, mainly regarding foot placement and pass/fail criteria, can be found in the literature. ${ }^{21}$ We conducted the SEBT in accordance with the study of Gribble $e t$ al. ${ }^{16}$ The SEBT was executed only in the ANT direction (SEBT-ANT) as the literature shows that this component of the SEBT has the strongest association with subsequent injury. ${ }^{16}{ }^{17}$ The subjects received a plenary instruction about the execution of the test. In accordance with the literature, they had to perform six practising trials for each leg. ${ }^{21}{ }^{22}$ To execute the SEBT-ANT, subjects had to stand on one foot with the most distal aspect of the weight-bearing foot at a starting line. With their free leg subjects had to reach slowly as far as possible in the ANT direction, slightly above a measuring tape on the floor, while maintaining the hands placed on their hips and their standing foot flat on the floor. The maximal reach was determined, by way of visual evaluation, at the point of maximal reach and administered with the nearest $0.5 \mathrm{~cm}$. The trial was rejected, and repeated, when the subject: (1) failed to maintain one legged stance with their foot flat on the floor, (2) failed to maintain balance during or directly after the test and (3) touched down with the reach foot. The test was repeated three times successfully for each leg. The measurements were conducted by a team of five trained fourth-year PETE students.

Leg length was determined for the purpose to normalise the SEBT-ANT score. Subjects lay on a mat table in supine position while a physical therapist measured, with a cloth tape, the distance between the most inferior aspect of the ANT superior iliac spine and the most distal portion of the lateral malleolus of the right and left leg. All measurements were conducted by the same therapist.

\section{Injury surveillance}

During the academic year (September 2015-June 2016), subjects registered newly sustained injuries on seven occasions. For practical purposes and to obtain a high response rate, the injury registrations were completed during the plenary coaching meetings. This led to injury registration intervals of five curricular weeks for injury registrations one to six, the final injury registration covered seven curricular weeks. Injuries had to be specified in terms of localisation, injury mechanism (acute or overuse), circumstances of the inciting event, contributing factors, type and duration. An injury was defined as any physical complaint that resulted in a subject being unable to fully take part in sporting activities for at least 1 day, also referred to as a time-loss injury. ${ }^{23}$ This data acquisition method has been used in previous studies. ${ }^{4}$ Ankle injuries were identified using the localisation (ankle), as no further diagnoses of the injuries were done and the literature shows that the type of the self-evaluated injuries are not accurate. ${ }^{24}$

\section{Data analysis and statistics}

The SEBT-ANT scores from the three trials were averaged and normalised for leg length for each leg. ${ }^{25}$ Data from the injury surveillance were used to categorise legs in the ankle injury (first injury involved the ankle) or no ankle injury (no injury or first injury did not involve the ankle) group.

To analyse the relationship between SEBT-ANT scores and subsequent ankle injury, independent-samples t-tests were used to analyse differences in SEBT-ANT scores 
Table 1 Subject characteristics

\begin{tabular}{|c|c|c|c|}
\hline & Male & Female & Total \\
\hline Subjects (N, \%) & $137(70)$ & $59(30)$ & 196 \\
\hline Age (year, SD) & $19.5(2.4)$ & $18.6(1.3)$ & $19.3(2.2)$ \\
\hline Weight (kg, SD) & $71.6(8.7)$ & $61.9(5.1)$ & $68.7(8.9)$ \\
\hline BMI (SD) & $21.7(2.2)$ & $21.5(1.8)$ & $21.6(2.1)$ \\
\hline \multicolumn{4}{|l|}{ Extracurricular sport participation } \\
\hline Exposure (hours/week, SD) & $5.5(3.5)$ & $5.7(5.3)$ & $5.6(4.1)$ \\
\hline Sports top 5 (N, \%) & $\begin{array}{l}\text { Soccer }(57,42) \\
\text { Fitness }(53,39) \\
\text { Running }(29,21) \\
\text { Martial arts }(10,7) \\
\text { Cycling }(8,6)\end{array}$ & $\begin{array}{l}\text { Fitness }(11,19) \\
\text { Running }(10,17) \\
\text { Hockey }(9,15) \\
\text { Soccer }(9,15) \\
\text { Gymnastics }(7,12)\end{array}$ & $\begin{array}{l}\text { Soccer }(66,34) \\
\text { Fitness }(64,33) \\
\text { Running }(39,20) \\
\text { Hockey }(12,6) \\
\text { Martial arts }(12,6)\end{array}$ \\
\hline
\end{tabular}

BMI, body mass index.

between men and women. Second, the relationship between normalised SEBT-ANT and subsequent ankle injury was assessed at the leg level using generalised estimating equations (GEEs) with gender and ankle injury history in the model as confounders and controlled for intrasubject relations (two limbs per subject). This analysis was also conducted for men and women separately, without gender in the model as a confounder, because women had higher normalised SEBT-ANT scores than men (table 1). In addition, a secondary analysis was performed with the exclusion of subjects where the first injury did not involve the ankle.

Third, the normalised SEBT-ANT scores were dichotomised using the average as the cut-off point. Finally, ORs were calculated using GEE analysis (with >mean as the reference group) with ankle injury history and gender

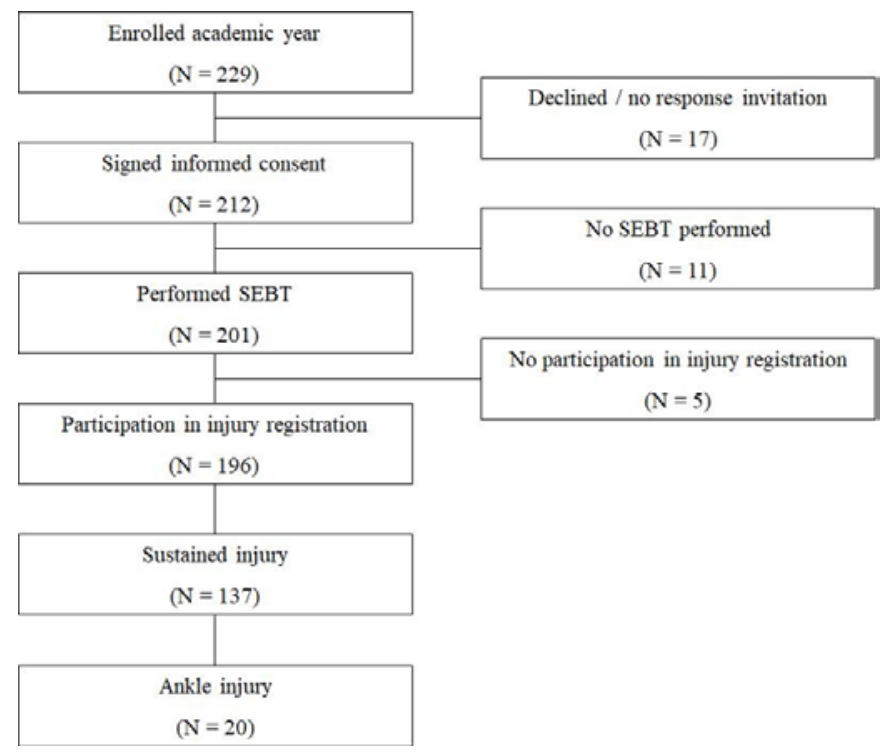

Figure 1 Flow chart of the inclusion of subjects $(n=196)$. SEBT, Star Excursion Balance Test. as a confounder in the model. The average score of the study sample was used as a cut-off point to exclude the possibility that a predefined cut-off point from the literature introduced a bias in the study, as the literature shows that of the SEBT protocol is often conducted in different ways $^{21}$ and different optimal cut-off points are found in different athletic populations (eg, 84\% of leg length in basketball players ${ }^{17}$ and $64 \%$ of leg length in soccer players ${ }^{20}$ ). Again, a secondary analysis was conducted with the exclusion of subjects where the first injury did not involve the ankle.

An alpha level of $\mathrm{p}<0.05$ was used to assess significance. Analyses were conducted using SPSS V.24.

\section{Patient and public involvement}

The study participants were not involved in the design of this study. No patient involvement.

\section{RESULTS}

In total 196 subjects were included in the analysis (figure 1) of which 137 men (70\%) and 59 women (30\%). Subject characteristics are presented in table 1. Results from the SEBT-ANT test are presented in table 2.

During the follow-up period, the researchers received 1111 of the 1372 expected injury registration forms. This indicates an overall response rate of $81 \%$, where the majority (51\%) of the subjects had a response rate of $100 \%$. In total $137(70 \%)$ subjects sustained one or more injuries, of which $20(15 \%)$ cases involved the ankle as the first injury (unilateral: $n=19$, bilateral: $n=1$ ). All the ankle injuries occurred acutely. Further details of the ankle injuries are presented in table 3 .

The relationship between normalised SEBT-ANT score and subsequent ankle injury was significant in the total group ( $\mathrm{OR}=1.11,95 \% \mathrm{CI}: 1.02$ to $1.22, \mathrm{p}=0.02)$ and in men $(\mathrm{OR}=1.14,95 \% \mathrm{CI}: 1.04$ to $1.26, \mathrm{p}<0.01)$, where 


\begin{tabular}{|c|c|c|c|c|}
\hline SEBT-ANT score & Total $(n=196)$ & Men $(n=137)$ & Women $(n=59)$ & $P$ value \\
\hline \multicolumn{5}{|l|}{ Absolute (cm) } \\
\hline Average & $64.02(5.79)$ & $64.63(6.12)$ & $62.60(4.68)$ & $<0.02^{*}$ \\
\hline Left & $64.15(6.15)$ & $64.86(6.35)$ & $62.50(5.36)$ & $.01^{*}$ \\
\hline Right & $63.89(5.89)$ & $64.40(6.28)$ & $62.71(4.72)$ & 0.07 \\
\hline \multicolumn{5}{|l|}{$\begin{array}{l}\text { Normalised (\% leg } \\
\text { length) }\end{array}$} \\
\hline Average & $65.88(5.52)$ & $65.11(5.54)$ & 67.67 (3.96) & $<0.01^{* *}$ \\
\hline Left & $66.01(5.64)$ & $65.34(5.86)$ & $67.55(4.82)$ & $.01^{*}$ \\
\hline Right & $65.76(5.40)$ & $64.88(5.67)$ & $67.79(4.06)$ & $<0.01^{* *}$ \\
\hline
\end{tabular}

${ }^{*}$ Significant at $\mathrm{p}<0.05,{ }^{*}$ significant at $\mathrm{p}<0.01$.

SEBT-ANT, Star Excursion Balance Test Anterior Reach.

lower SEBT-ANT scores indicated increased ankle injury odds. This relationship was not significant in women $(\mathrm{OR}=1.05,95 \% \mathrm{CI}: 0.86$ to $1.28, \mathrm{p}=0.66$ ) (table 4$)$. The secondary analysis, only including legs for subjects where the first injury involved the ankle and subjects without any injury during the follow-up period, produced comparable results (total: $\mathrm{OR}=1.10,95 \% \mathrm{CI}$ : 1.02 to $1.19, \mathrm{p}=0.01$; men: $\mathrm{OR}=1.11,95 \%$ CI: 1.02 to $1.22, \mathrm{p}=0.02$; women: $\mathrm{OR}=1.09$, 95\% CI: 0.94 to $1.26, \mathrm{p}=0.26$ ).

For the total group, a below average SEBT-ANT score was not statistically significant associated with increased ankle injury odds ( $\mathrm{OR}=2.43,95 \%$ CI: 0.94 to $6.29, \mathrm{p}=0.07$ ). In men, legs with a below average normalised SEBT-ANT score had sevenfold increased odds to sustain a subsequent ankle injury compared with legs with an above average score (OR=7.06, 95\% CI: 1.43 to $34.92, \mathrm{p}=0.02)$. A below average SEBT-ANT was not associated with increased ankle injury odds in women $(\mathrm{OR}=0.72,95 \% \mathrm{CI}$ : 0.19 to $2.71, \mathrm{p}=0.62$ ) (table 5). The secondary analysis, only including legs for subjects where the first injury involved the ankle and subjects without any injury during the follow-up period, produced comparable results (total: $\mathrm{OR}=2.58,95 \%$ CI: 1.03 to $6.50, \mathrm{p}=0.04$; men: $\mathrm{OR}=6.49$, $95 \%$ CI: 1.33 to $31.82, \mathrm{p}=0.02$; women: $\mathrm{OR}=0.93,95 \% \mathrm{CI}$ : 0.23 to $3.71, \mathrm{p}=0.92$ ).

\section{DISCUSSION}

The purpose of this study was to investigate whether dynamic balance of the ankle, measured with the SEBT-ANT, is a risk factor for ankle injuries in PETE students. The main finding is that below average normalised SEBT-ANT scores were associated with a sevenfold odds for subsequent ankle injuries in men. In contrast, no association between SEBT-ANT scores and ankle injury was found in women. This indicates that gender was an effect modifier in the relationship between dynamic balance and ankle injury likelihood.

\section{Comparisons with literature}

Ankle injuries

Our study shows that the ankle is involved in $15 \%$ of the first injuries, which is in accordance with the literature. Previous studies in male and female first-year PETE students report ankle injury rates between $12 \%$ and 17\%. ${ }^{4-8}$ Furthermore, a review study by Fong et $a l^{26}$ showed that in $11.2 \%-20.8 \%$ of all the injuries the ankle is the involved body site. ${ }^{26}$ Because ankle injuries mostly consist of ankle sprains, ${ }^{26}$ our results can also be compared with results from studies that focused on ankle sprains. Hootman et $a l^{27}$ conducted an analysis on data from 16 years of injury surveillance in male and female collage athletes in 15 different sport, covering 182.000 injuries, and showed that in $14.9 \%$ of the cases the injury involved a sprain of ankle. ${ }^{27}$

\section{SEBT-ANT scores}

In our study an average ANT of $65.1 \%$ and $67.7 \%$ of leg length was found for men and women, respectively. In the literature, mean values of $65.6 \%$ to $84.1 \%$ are found for men and $70.3 \%$ to $81.4 \%$ for women. ${ }^{14-17212829}$ This indicates that our results are relatively low compared with the literature. A study by Plisky $e t a l^{21}$ showed that the application of the SEBT protocol is often used in different ways, which influences the results. ${ }^{21}$ The most observed differences are: (1) the extent that subject is allowed to touch down with the reach foot, (2) the extent that stance foot movement is allowed and (3) stance foot positioning. ${ }^{21}$ In our study, subjects were instructed not to touch down with the reach foot and place their stance foot against the starting line. Besides, we instructed subjects to maintain their hands places on the hip. The extent that arm movement is allowed is often unspecified in literature. These three factors may explain the lower scores in our study. Gribble $e a^{16}$ conducted the SEBT-ANT in a similar way as in our study and found an average score of $69.0 \%$ in male high school and collegiate football players, which is $3.9 \%$ higher than the men in our study. An explanation for this difference may be that high level football players 
Table 3 Specifications of the self-evaluated ankle injuries

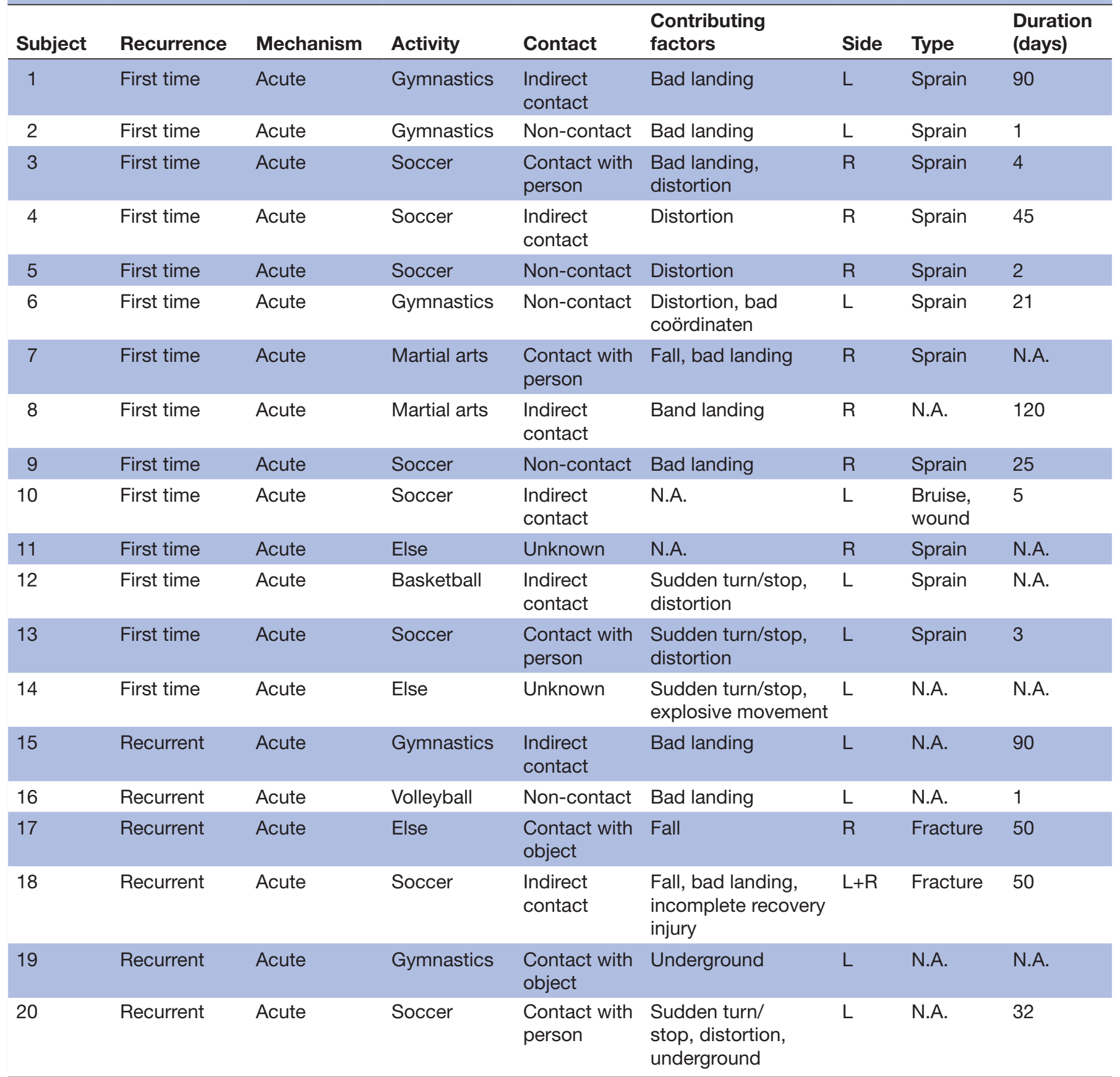

L, left;N.A, not available; R, right.

probably have a higher physical performance, include dynamic balance, compared with our heterogeneous sport population of PETE students.

\section{Risk factor}

Our study showed a sevenfold increased ankles injury odds for legs with a below average normalised SEBT-ANT scores in men. Our study found a higher odds compared with the study by Gribble et al. ${ }^{16}$ Gribble et al used a normalised SEBT-ANT cut-off score of $67.2 \%$ and found a significant OR of 2.84 for lateral ankle sprain injuries in male football players $(n=539) .{ }^{16}$ The fact that Gribble et $a l^{16}$ had approximately twice the sample size and injury cases compared with our study, included only male soccer players and determined the cut-off score using ROC analysis may help to explain the differences in results.

Ko et $a t^{20}$ investigated dynamic balance as a risk factor for ankle injuries in adolescent male and female soccer players and found, an almost significant, fourfold increased odds for ankle injury in subjects with lower SEBT-ANT scores $(<64 \%)$. This is in agreement with the overall results in our study. Differences in subjects age, type of sport participation, the used cut-off score and the 
Table 4 Normalised SEBT-ANT scores (mean, SD) for non-injured and injured male legs (non-injury: $n=262$, injury: $n=12$ ) and female legs (non-injury: $n=109$, injury: $n=9$ ) and the results from the GEE analysis

\begin{tabular}{|c|c|c|c|c|}
\hline & \multicolumn{2}{|c|}{ Normalised SEBT-ANT score } & \multicolumn{2}{|l|}{ GEE analysis } \\
\hline & Non-injury & Injury & OR $(95 \% \mathrm{Cl})$ & $P$ value \\
\hline Men & $65.30(5.66)$ & $61.00(6.54)$ & 1.14 (1.04 to 1.26$)$ & $<0.01^{\star \star}$ \\
\hline Total & 66.02 (5.39) & $63.42(7.13)$ & 1.11 (1.02 to 1.22$)$ & $0.02^{*}$ \\
\hline
\end{tabular}

*Significant at $\mathrm{p}<0.05,{ }^{*}$ significant at $\mathrm{p}<0.01$.

SEBT-ANT, Starr Excursion Balance Test Anterior Reach.

proportion of males and females in the study may help to explain the difference in observed odds for the subgroups. Attenborough et $a l^{19}$ found no relationship between the SEBT-ANT score and subsequent ankle injury in female netball players, ${ }^{19}$ which corresponds with the findings in female PETE students in our study.

Other studies that used the SEBT-ANT as a risk factor for injuries are conducted by Plisky $e t a l^{17}$ and de Noronha et $a l^{30}$ Plisky et $a l^{17}$ used a normalised SEBT-ANT cut-off score of $84.3 \%$ in male and females basketball players $(n=235)$ and found ORs in the range of 1.8-4.1 for lower extremity injuries ${ }^{17}$ in women. In this study, no significant relationship was found in men, which is the opposite of the result in our study. However, Plisky et $a l^{17}$ analysed the SEBT-ANT score as a risk factor for lower extremity injuries in general, not as a risk factor for ankle injuries. This is a major difference, which helps to explain the differences in results. de Noronha $e t a l^{30}$ conducted a study in active university students and did not find a relationship between normalised SEBT-ANT and subsequent ankle injury. ${ }^{30}$ However, it is difficult to compare this study with our study because regular university students are probably less physically active than PETE students.

In summary, in accordance with several studies, our study indicated that lower scores on the SEBT-ANT indicated increased odds for subsequent ankle injury in males,

Table 5 Number of ankle injuries (N, \%) per group and results from the GEE analysis

\begin{tabular}{|c|c|c|c|c|}
\hline & \multirow[b]{2}{*}{ Non-injury } & \multicolumn{3}{|c|}{ GEE analysis } \\
\hline & & Injury & OR $(95 \% \mathrm{Cl})$ & $\begin{array}{l}\mathbf{P} \\
\text { value }\end{array}$ \\
\hline \multicolumn{5}{|l|}{ Men } \\
\hline$<$ mean & $113(41)$ & $10(4)$ & 7.06 (1.43 to 34.92$)$ & $0.02^{*}$ \\
\hline$>$ mean & $149(54)$ & $2(1)$ & - & \\
\hline \multicolumn{5}{|l|}{ Women } \\
\hline$<$ mean & $54(46)$ & $4(3)$ & 0.72 (0.19 to 2.71$)$ & 0.62 \\
\hline$>$ mean & $55(47)$ & $5(4)$ & - & \\
\hline \multicolumn{5}{|l|}{ Total } \\
\hline$<$ mean & $167(43)$ & $14(4)$ & 2.43 (0.94 to 6.29) & 0.07 \\
\hline >mean & $204(52)$ & $7(2)$ & - & \\
\hline
\end{tabular}

*Significant at $p<0.05$. not in females. In our study, this indicates that gender is an effect modifier in this relationship. An explanation for this finding may be as following. The SEBT incorporates components of coordination, flexibility and strength of the lower extremities. ${ }^{17} 31$ These are all important intrinsic factors related to injury risk, ${ }^{3}$ where better coordination, flexibility and strength represents a lower injury risk. Several studies indicate that, in general, males and females have similar SEBT-ANT scores. ${ }^{1728}{ }^{30}$ Our study presents higher SEBT-ANT scores in female subjects. This may point out that female subjects in our study had a relative 'better' dynamic balance than male subjects and therefore were less prone to ankle injury.

\section{Strength and limitations}

The strength of our study is that we used a prospective study design with a relative long follow-up period. Furthermore, our study used a more sophisticated analysis (GEE analysis at the leg level and controlled the model by person and previous ankle injury) compared with other studies on the same topic. Another strength of this study is that, with an overall response rate of $81 \%$ and 51 subjects with a $100 \%$ response rate, our study managed to reach a relative high response rate.

This study also has some limitations that need to be addressed. First, we used a self-evaluation registration of injuries. To minimise this limitation, we used a clear injury definition and a relatively short recall period. Furthermore, we used localisation for the identification of self-reported ankle injuries as these are more reliable parameters than other detailed characteristics of self-reported injuries (eg, type). ${ }^{24}$ Second, we did not determine the inter-rater reliability of our SEBT test group. The SEBT has good inter-rater reliability, but is also often used in different manners. ${ }^{21}$ This indicates that our results from the SEBT have limitations for comparisons with other studies. Third, the overall response rate of $81 \%$ can be considered as good. Nevertheless, the $19 \%$ of non-response might bias our results. Fourth, in accordance with common injury research methodology, we used linear regression analysis to evaluate the significance of risk factors. ${ }^{32}$ However, recent literature pointed out the importance of non-linear analysis for risk factors and addressed the complex inter-relations between factors. ${ }^{33-35}$ Fifth, we had a relative low number of ankle 
injury cases in the two subgroups (men and women). This indicates a limited statistical power of the risk factor analysis for the subgroups. Sixth, we determined cut-off scores with the average SEBT-ANT scores. These cut-off scores have limited clinical relevance as they are based on a single sample of PETE students. Seventh, the analysis in this study were not controlled for body mass index (BMI). Several subjects (14\%) had missing values for BMI. BMI was unsuitable to use as a confounder in the analysis as a sensitivity analysis indicated that an analysis with BMI as a confounder demonstrated decreased robustness of the results due to the amount of missing values. Finally, in our analysis, we did not discriminate between types or severity of the ankle injury. In the literature, dynamic balance of the ankle is considered a risk factor for specifically ankle sprains. Our study may have included other types of ankle injuries and underestimated the true relationship between SEBT-ANT and subsequent ankle injury. These limitations should be kept in mind when interpreting the results from this study.

Future studies are advised to: (1) determine normative values for the SEBT-ANT in PETE students and determine optimal cut-off scores to identify students at risk for an ankle injury, (2) investigate which (combination of) balance tests have the strongest relation with ankle injury risk, (3) use more precise data regarding the ankle injury (eg, professional diagnosis of injuries, specific injury type), (4) investigate whether non-linear relations exist in the relations between ankle balance and ankle injury risk or (5) assess whether preventive measures (eg, a neuromuscular training programme or the use of bracing) reduces ankle injury risk in PETE students.

\section{CONCLUSION}

This study indicates that lower scores on the normalised SEBT-ANT, as a measure for dynamic balance, are associated with an increased odds for subsequent ankle injury in male PETE students. Therefore, the SEBT-ANT has potential as a screening tool for ankle injury risk in male PETE students. However, before implementation of the SEBT-ANT as a screening tool normative values and optimal cut-off scores should be determined. By doing so preventive measures can be targeted efficiently and effectively. For instance, male students with a positive outcome for the SEBT-ANT can be advised to participate in a neuromuscular training programme $\mathrm{e}^{36}$ or to use ankle bracing during sport participation. ${ }^{37} 38$

\footnotetext{
Author affiliations

${ }^{1}$ Amsterdam University of Applied Sciences, Centre for Applied Research in Sports and Nutrition, Amsterdam, Netherlands

${ }^{2}$ Codarts University College for the Arts, Rotterdam, Zuid-Holland, The Netherlands ${ }^{3}$ Performing Artist and Athlete Research Lab (PEARL), Rotterdam, Netherlands ${ }^{4}$ Erasmus MC Medical University Center Rotterdam, Department General Practice, Rotterdam, Netherlands

${ }^{5}$ Rotterdam Arts and Science Lab (RASL), Rotterdam, Netherlands

${ }^{6}$ Amsterdam Collaboration on Health and Safety in Sports \& Department of Public and Occupational Health, Amsterdam Movement Science, VU University Medical Center, Amsterdam, North Holland, The Netherlands
}

${ }^{7}$ UCT/MRC Research Unit for Exercise Science and Sports Medicine (ESSM), Department of Human Biology, Faculty of Health Sciences, University of Capetown, Capetown, South-Africa

${ }^{8}$ School of Physical Education, Faculty of Physical Therapy \& Occupational Therapy, Universidade Federal de Minas Gerais, Belo Horizonte, Brazil

\section{Twitter Evert Verhagen @evertverhagen}

Acknowledgements We would like to thank Sander Plomp and the study counsellors (Heleen Kerkhoff, Jeroen Laan, Chris van de Kant, Stephanie Hermans) for their contribution to the data acquisition. Also, we wish to thank Jos Twisk for the advice on the statistical analysis.

Contributors SB and JS designed the study. SB coordinated the study and conducted the data analysis. SB, JS and EV interpreted the results. All authors were involved in drafting and editing the manuscript, led by SB. All authors approved the final manuscript.

Funding This study was supported by funding from the Taskforce Applied Research (SIA, reference number 2013-15-12P).

Competing interests None declared.

Patient consent for publication Not required.

Ethics approval The study procedures were approved by the ethical committee of the Academic Medical Centre in Amsterdam (reference number:W15_224 \# 15.0266).

Provenance and peer review Not commissioned; externally peer reviewed.

Data availability statement The dataset analysed during the current study is available from the corresponding author on reasonable request.

Open access This is an open access article distributed in accordance with the Creative Commons Attribution Non Commercial (CC BY-NC 4.0) license, which permits others to distribute, remix, adapt, build upon this work non-commercially, and license their derivative works on different terms, provided the original work is properly cited, appropriate credit is given, any changes made indicated, and the use is non-commercial. See: http://creativecommons.org/licenses/by-nc/4.0/.

ORCID iD

Sander Bliekendaal http://orcid.org/0000-0002-7978-1828

\section{REFERENCES}

1 Das P, Horton R. Rethinking our approach to physical activity. The Lancet 2012;380:189-90.

2 Bouchard CE, Shephard RJ, Stephens TE. Physical activity, fitness, and health: international proceedings and consensus statement 1994.

3 Meeuwisse WH, Tyreman $\mathrm{H}$, Hagel B, et al. A dynamic model of etiology in sport injury: the recursive nature of risk and causation. Clin J Sport Med 2007;17:215-9.

4 Bliekendaal S, Goossens L, Stubbe JH. Incidence and risk factors of injuries and their impact on academic success: a prospective study in petE students. Scand J Med Sci Sports 2017;27:1978-85.

5 van Mechelen W, Hlobil H, Incidence KHC. Severity, aetiology and prevention of sports injuries. A review of concepts. Sports Med 1992;14:82-99.

6 van Beijsterveldt A-M, Richardson A, Clarsen B, et al. Sports injuries and illnesses in first-year physical education teacher education students. BMJ Open Sport Exerc Med 2017;3.

7 Goossens L, Verrelst R, Cardon G, et al. Sports injuries in physical education teacher education students. Scand J Med Sci Sports 2014;24:683-91.

8 Mukherjee S. Sports injuries in University physical education teacher education students: a prospective epidemiological investigation. $J \mathrm{~J}$ Sport Med 2014;1:1-9.

9 Verstappen F, Twellaar M, Hartgens F, et al. Physical fitness and sports skills in relation to sports injuries. A four-year prospective investigation of sports injuries among physical education students. Int J Sports Med 1998;19:586-91.

10 Beynnon BD, Murphy DF, Alosa DM. Predictive factors for lateral ankle Sprains: a literature review. J Athl Train 2002;37:376-80.

11 Doherty C, Delahunt E, Caulfield B, et al. The incidence and prevalence of ankle sprain injury: a systematic review and metaanalysis of prospective epidemiological studies. Sports Med 2014;44:123-40. 
12 Murphy DF, Connolly DA, Beynnon BD. Risk factors for lower extremity injury: a review of the literature. $\mathrm{Br} J$ Sports $\mathrm{Med}$ 2003;37:13-29.

13 Dallinga JM, Benjaminse A, Lemmink KAPM. Which screening tools can predict injury to the lower extremities in team sports? Sports Med 2012;42:791-815.

14 Engquist KD, Smith CA, Chimera NJ, et al. Performance comparison of Student-Athletes and general college students on the functional movement screen and the $Y$ balance test. J Strength Cond Res 2015;29:2296-303.

15 de la Motte SJ, Lisman P, Sabatino M, et al. The relationship between functional movement, balance deficits, and previous injury history in deploying marine Warfighters. J Strength Cond Res 2016;30:1619-25.

16 Gribble PA, Terada M, Beard MQ, et al. Prediction of lateral ankle Sprains in football players based on clinical tests and body mass index. Am J Sports Med 2016;44:460-7.

17 Plisky PJ, Rauh MJ, Kaminski TW, et al. Star excursion balance test as a predictor of lower extremity injury in high school basketball players. J Orthop Sports Phys Ther 2006;36:911-9.

18 Hegedus EJ, McDonough SM, Bleakley C, et al. Clinician-friendly lower extremity physical performance tests in athletes: a systematic review of measurement properties and correlation with injury. Part 2 -the tests for the hip, thigh, foot and ankle including the StAR excursion balance test. Br J Sports Med 2015;49:649-56.

19 Attenborough AS, Sinclair PJ, Sharp T, et al. The identification of risk factors for ankle sprains sustained during netball participation. Physical Therapy in Sport 2017;23:31-6.

20 Ko J, Rosen AB, Brown CN. Functional performance tests identify lateral ankle sprain risk: a prospective pilot study in adolescent soccer players. Scand J Med Sci Sports 2018;28:2611-6.

21 Plisky PJ, Gorman PP, Butler RJ, et al. The reliability of an instrumented device for measuring components of the StAR excursion balance test. N Am J Sports Phys Ther 2009;4:92-9.

22 Kinzey SJ, Armstrong CW. The reliability of the star-excursion test in assessing dynamic balance. J Orthop Sports Phys Ther 1998;27:356-60.

23 Fuller CWet al. Consensus statement on injury definitions and data collection procedures in studies of football (soccer) injuries. $\mathrm{Br} \mathrm{J}$ Sports Med 2006;40:193-201.

24 Gabbe BJet al. How valid is a self reported 12 month sports injury history? Br J Sports Med 2003;37:545-7.
25 Gribble PA, Hertel J. Considerations for normalizing measures of the StAR excursion balance test. Meas Phys Educ Exerc Sci 2003; 7:89-100.

26 Fong DT-P, Hong Y, Chan L-K, et al. A systematic review on ankle injury and ankle sprain in sports. Sports Medicine 2007;37:73-94.

27 Hootman JM, Dick R, Agel J. Epidemiology of collegiate injuries for 15 sports: summary and recommendations for injury prevention initiatives. J Athl Train 2007;42:311-9.

28 Alnahdi $\mathrm{AH}$, Alderaa AA, Aldali AZ, et al. Reference values for the $Y$ balance test and the lower extremity functional scale in young healthy adults. J Phys Ther Sci 2015;27:3917-21.

29 Lee B-G, Lee J-H. Immediate effects of ankle balance taping with kinesiology tape on the dynamic balance of young players with functional ankle instability. THC 2015;23:333-41.

30 de Noronha M, Franca LC, Haupenthal A, et al. Intrinsic predictive factors for ankle sprain in active university students: a prospective study. Scand J Med Sci Sports 2013;23:541-7.

31 Earl JE, Hertel J. Lower-Extremity muscle activation during the StAR excursion balance tests. J Sport Rehabil 2001;10:93-104.

32 Bahr R, Holme I. Risk factors for sports injuries -- a methodological approach. Br J Sports Med 2003;37:384-92.

33 Verhagen E, Load GT. Capacity and health: critical pieces of the holistic performance puzzle. Br J Sports Med 2018.

34 Bittencourt NFN, Meeuwisse WH, Mendonça LD, et al. Complex systems approach for sports injuries: moving from risk factor identification to injury pattern recognition - narrative review and new concept. Br J Sports Med 2016;50:1309-14.

35 Gabbett TJ. The training - injury prevention paradox: should athletes be training smarter and harder? $\mathrm{Br} J$ Sports Med 2016;50:273-80.

36 Verhagen E, van der Beek A, Twisk J, et al. The effect of a proprioceptive balance board training program for the prevention of ankle Sprains. Am J Sports Med 2004;32:1385-93.

37 Janssen $\mathrm{KW}$, van Mechelen W, Verhagen EA. Bracing superior to neuromuscular training for the prevention of self-reported recurrent ankle sprains: a three-arm randomised controlled trial. $\mathrm{Br} J$ Sports Med 2014:bjsport-092947.

38 Barelds I, van den Broek AG, Huisstede BMA. Ankle bracing is effective for primary and secondary prevention of acute ankle injuries in athletes: a systematic review and meta-analyses. Sports Medicine 2018;48:2775-84. 